\title{
Weather to evacuate?
}

To THE EDITOR: Woods and colleagues provide a timely and descriptive reminder of cyclone Yasi and the 2010-2011 summer. ${ }^{1}$ The evacuation of the hospitals on the Cairns foreshore, a decision made by the Queensland Premier, was the largest hospital evacuation in Australian history. The capability to successfully aeromedically transport 297 patients $1800 \mathrm{~km}$, in a window of 22 hours, without loss of life or reported adverse clinical incident, was testament to the entire Queensland emergency management system.

The capability
to successfully
aeromedically
transport 297
patients
$1800 \mathrm{~km}$, in a
window of 22
hours ... was
testament to
the entire
Queensland
emergency
management
system

75 Young et al
While too many agencies were involved to name, a major coordination effort was required by the State Health Emergency Coordination Centre, Retrieval Services Queensland, Australian Defence Force, Queensland Ambulance Service and the Cairns and Hinterland Health Service District. The significance of these roles was recognised with several Queensland Government agencies sharing a Queensland Premier's Award.

The decision to evacuate hospitals is not without significant risk. The timeline in the article suggests that the decision to evacuate was made because of a Category 3 cyclone approaching Cairns. This undersells the preparedness and resilience of the North Queensland community and Queensland Health. Although, at the time of the decision, Yasi was a

Category 3 cyclone, the decision to 
evacuate was based on the prediction by the Bureau of Meteorology that Yasi would be crossing as a Category 5 cyclone with wind speeds of over $290 \mathrm{~km}$ per hour, an eye more than $100 \mathrm{~km}$ wide, a storm front more than $650 \mathrm{~km}$ wide and a storm surge of over $6 \mathrm{~m}$. Yasi was the largest cyclone to ever cross the Australian coast, and was similar in size to Hurricane

Katrina in the United States in 2005.

Every disaster provides learning opportunities. Further improvements in the Queensland Health emergency management system have already been made in readiness for the next summer, with more expected after ongoing detailed analysis.

Jeannette R Young Chief Health Officer

Mark S Elcock State Medical Director, Retrieval Services Queensland

Peter J Aitken Senior Medical Coordinator Disaster Management, Retrieval Services Queensland

Queensland Health, Brisbane, QLD.

Peter_Aitken@health.qld.gov.au

Competing interests: No relevant disclosures.

doi: 10.5694/mjal2.10306

1 Woods CE, Goodman D, Mills J, et al. Weather to evacuate? Med J Aust 2011; 195: 712-713. 